\title{
紫根抽出液の化粧品への応用
}

\author{
二子石 広 猛* 安 部 隆*

\section{The Application of the Extractive of Lithospermi Radix for Cosmetic Formulation}

\author{
Hirotake FutAgOISHI* Takashi ABE*
}

This study was conducted for the purpose of introducing the active ingredient obtained from Lithospermi Radix into cosmetic formulation. The experiment was made on the method of extraction as well as the clinical evaluation. As the results, the effective substance is considered to be obtainable by macerating with isopropyl myristate. This extract has expectation of being effective to remedy of slight acne vulgaris and acute eczema.

\section{1. 緒言}

紫根はムラサキ (Lithospermum erythrorhizon) [科 名, ムラサキ科 (Borraginaceae)] の根部である。本植 物は極東に分布していて，ヨーロッパに生育する西洋ム ラサキ (Lithospermum officinale) に類以している。 紫根は古来より漢方薬として有名であり, 紫雲膏の 1 成 分である。皮膚科領域1)では, 紫雲膏は外傷, 凍傷, 潰 瘍, 火傷, 湿疹等に使用されていた。紫根は局方 2 部に 記載の生薬である。薬理作用 2,3$)$ として, 鎮痛, 抗炎症, 止血, 抗菌性等があるといわれている。紫根の有効成分
5,6,7)はナフトキノン誘導体である。これらは Table-1 に 示した。有効成分シコニン [ I ] は黒田によって分離さ れ, Brockmann ${ }^{8}$ がアルカンナより分離したアルカニ ンの光学対掌体であることも知られている。紫雲高をつ くるには紫根を植物油や脂肪の混合物中へ $140^{\circ} \mathrm{C}$ で浸 漬されるとされている4)。しかし，抽出された有効成分

* 鐘ヶ淵紡績株式会社 化粧品研究所(神奈川県小田 原市寿町 5-3-28)

* Kanegafuchi Spinning Co., Ltd. Cosmetic Laboratory, 5-3-28 Kotobuki-Cho OdawaraCity, Kanagawa, Japan

Table-1 Naphthoquinone Derivatives<smiles>CC(C)=CCC(O)C1=CC(=O)c2c(O)ccc(O)c2C1=O</smiles>

$\mathrm{R}$
( I ) $-\mathrm{H}$
Shik on in
(II) $-\mathrm{C} \mathrm{OCH}$
(III) $-\mathrm{CO}-\mathrm{CH} \stackrel{\mathrm{CH}_{3}}{\longrightarrow} \mathrm{CH}_{3}$
Acetyl-shikonin
Isobutyl-shikonin
(IV) $-\mathrm{CO}-\mathrm{CH}=\mathrm{C} \overbrace{\mathrm{CH}_{3}}^{\mathrm{CH}_{3}} \beta \cdot \beta$-Dimethylacry1-shikonin
(v) $-\mathrm{CO}-\mathrm{CH}_{2}-\mathrm{C} \bigwedge_{\mathrm{OH}}^{-\mathrm{CH}_{3}}$
$\beta \cdot$ Hydroxy isovaleryl-shikonin
(VI) $-\mathrm{CO}-\mathrm{CH}_{2}-\underset{\mathrm{CH}_{3}}{\mathrm{C}}=\mathrm{C}_{\mathrm{CH}_{3}}^{\mathrm{CH}_{3}}$ Teracryl-shikonin 
の安定性に関して, 若干問題があるとされている4)。ま た, 得られた抽出液を広範に化粧品に利用することも困 難であった。化粧品に抽出液を適用するためには，化粧 品原料である流動パラフィン, エステル, 植物油 etcを 利用するのが有利である。本研究は紫根の安定にして有 用なる抽出液を得る目的で行なった。

\section{2. 実験および実験結果}

\section{$2 \cdot 1$ 試 料}

抽出剤として, 市販の流動パラフィン（セイボルトー 粘度一70), ミリスチン酸イソプロピル, オリーブ油, ヘキサデシルアルコール, オレイン酸, スクワラン, ヒ マシ油, ゴマ油を使用した。

\section{$2 \cdot 2$ シコニンの定量}

文献7)公知の方法で得たシコニンを抽出液中の含有シ コニンの定量分析の基準物質として使用した。紫根より 分離したシコニンの性質は Table-2 に示した。 $519 \pm 2$ $\mathrm{m} \mu, 279 \pm 1 \mathrm{~m} \mu$ における吸光度を分離したシコニンの アルコール溶液または, n-Hexane 溶液について測定し， 検量線を作成した。抽出液は含有シコニンの濃度と安定 性に注目して検量線と吸光度から比較した。生薬 $10 \mathrm{~g}$ を 各抽出剂 $100 \mathrm{~m} l$ で種々の条件で抽出した。抽出液をア ルコールまたは, n-Hexane で $2 \%(\mathrm{v} / \mathrm{v})$ に希釈し, そ

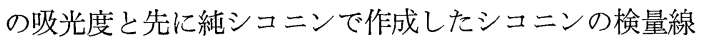
から抽出液の含有シコニン濃度を測定した。
Table-2 Properties of Shikonin (I)

\begin{tabular}{|c|c|c|}
\hline $\begin{array}{l}\text { Appearance } \\
\text { M. P. }\end{array}$ & \multicolumn{2}{|c|}{$\begin{array}{l}\text { Violet needle crystal } \\
: 146^{\circ} \mathrm{C}^{*}\end{array}$} \\
\hline UV spectra & $: \lambda_{\max }^{\text {ethanol }}$ & $279 \mathrm{~m} \mu$ \\
\hline Visible ray spectra: & $\lambda_{\max }^{\text {ethanol }}$ & $519 \mathrm{~m} \mu$ \\
\hline IR & $\begin{array}{r}3500 \mathrm{~cm}^{-1} \\
1600 \mathrm{~cm}^{-1}\end{array}$ & $\begin{array}{l}\text {-hydroxy } \\
\text {-keton(chloroform) }\end{array}$ \\
\hline Solubility & \multicolumn{2}{|c|}{$\begin{array}{l}\text { Soluble-Benzene, Ether Ethan } \\
\text { ol, etc insoluble- } \mathrm{H}_{2} \mathrm{O}\end{array}$} \\
\hline
\end{tabular}

* Literature 7 ) $147 \sim 149^{\circ} \mathrm{C}$

\section{$2 \cdot 3$ 抽出剂によって抽出されるシコニン量の比較}

生薬を $10 \mathrm{~g}$, 抽出剤を $100 \mathrm{~m} l$ とし, Table-3 に示す ような条件で抽出液を得た。伝統的方法では紫雲高で使 用しているヒマシ油及びゴマ油を使用して，生薬を 140 ${ }^{\circ} \mathrm{C}$ の抽出剤に加え, 5 分間放置し, 沪別後, 水にて冷 却し, 抽出液を得た。その結果 Fig.-1 から判るよう に，冷浸法によるミリスチン酸イソプロピルは伝統的高 温抽出によるゴマ油よりも抽出効果大と思われる。高温 抽出によるゴマ油およびヒマシ油使用の際には，抽出さ れたシコニンはむしろ不安定なることも知られている4)。 さらに冷浸法による 6 種の抽出剤中ではミリスチン酸イ ソプロピルが最も有効である。さらに Fig.-1 からヒマ シ油中よりもオレイン酸中にシコニン含有量が多いこと が判る。

Table-3 Experimental conditions of extraction

\begin{tabular}{|c|c|c|c|}
\hline Method & Time & Temperature & Menstruum \\
\hline Traditional method & 5 minutes & $140^{\circ} \mathrm{C}$ & $\begin{array}{l}\text {-Sesame Oil } \\
\text {-Castor Oil }\end{array}$ \\
\hline Maceration method & 24 hours & Room temperatue & $\begin{array}{l}\text {-Isopropyl myristate } \\
\text { Olive Oil } \\
\text { Liquid Paraffin } \\
\text { Hexadecyl alcohol } \\
\text { Squalane } \\
\text {-Oleic acid }\end{array}$ \\
\hline
\end{tabular}

\section{$2 \cdot 4$ 各抽出液中のシコニンの安定性}

ミリスチン酸イソプロピル， ヘキサデシルアルコー ル, オレイン酸, スクワランの 4 種の抽出剤中のシコニ ンの安定性について検討した。抽出液は冷浸法にて得 た。抽出液は $45^{\circ} \mathrm{C}$ に保ち， 3 ケ月間一定の時間に測定 した。Fig.-2 に示すように，時間の経過とともにシコ ニン量の減少の傾向がみられる。 3 力月後も減少の過程 にあるようである。ミリスチン酸イソプロピル中のシコ
ニンの残存率は $96.1 \%$ であり，4種の抽出剤のうち最 大である。

\section{$\mathbf{2 \cdot 5}$ 冷浸時間とシコニン量の関係}

$2 \cdot 3,2 \cdot 4$, の実験結果にかんがみ, 以下の実験はミリ スチン酸イソプロピルについて行なった。Fig.-3で 519 $\pm 1 \mathrm{~m} \mu$ における測定から得る結果を，Fig.-4では 279 $\pm 2 \mathrm{~m} \mu$ における測定から得る結果を示した。Fig.-3, 


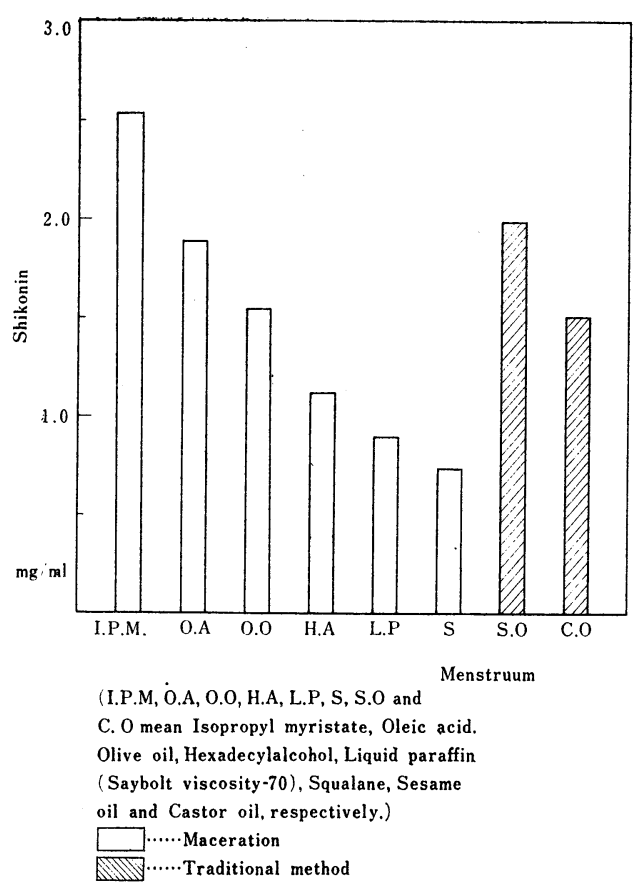

Fig.-1 Shikonin content in the extractives with various menstrua (key band $519 \pm 2 \mathrm{~m} \mu)$

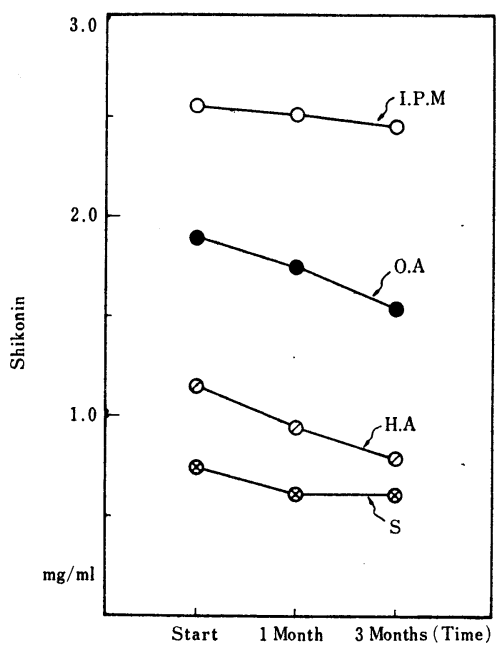

Fig.-2 Stability of shikonin in the extractives (key band $519 \pm 2 \mathrm{~m} \mu$ )

Fig.-4 から判るように, 抽出液中のシコニン含有量は 時間経過とともに増加するが，72時間目で最大となり， あとは一定になるようである。

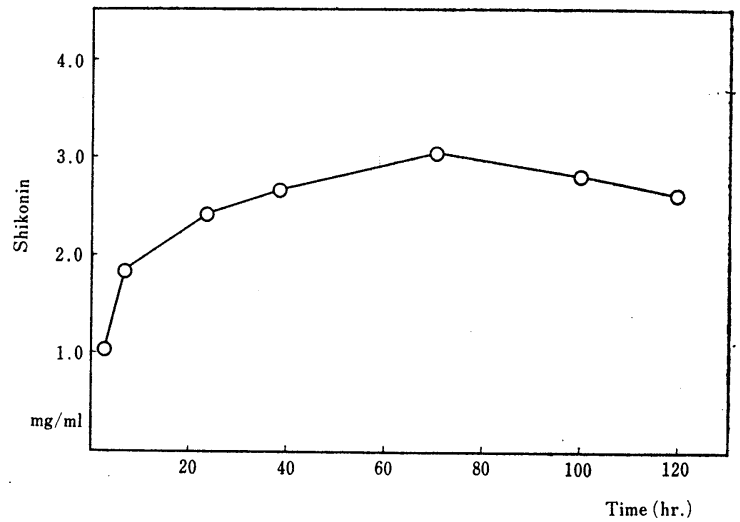

Fig.-3 Change of amount of shikonin by the maceration time. (key band $519 \pm 2 \mathrm{~m} \mu$ )

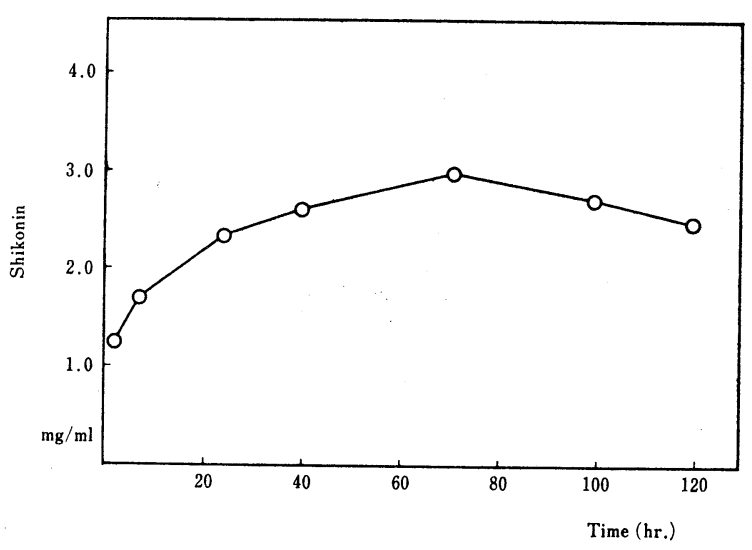

Fig. -4 Change of amount of shikonin by the maceration time. (key band $279 \pm 1 \mathrm{~m} \mu$ )

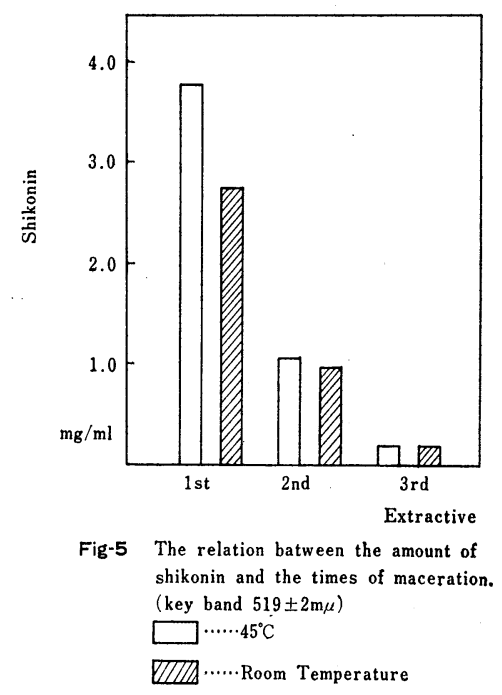




\section{$2 \cdot 6$ シコニン量と冷漫回数の関係}

シコニン量と冷浸回数との関係は Fig.-5 に示した。 第 1 回目の抽出液中にほとんどの有効成分が抽出される と考えられ，第 3 回目の抽出液中では非常に減少する。 又抽出に対する温度の影響を知るため $45^{\circ} \mathrm{C}$ と室温で比 較したが, $45^{\circ} \mathrm{C}$ と室温の間では, 温度効果は大きいも のとはいえないようである。

\section{$2 \cdot 7$ 再冷浸とシコニン量の関係}

再冷浸の場合, 第 1 回目と第 2 回目の抽出液中のシコ ニンの量は Fig.-6, Fig.-7 に示してあるが，前後の抽

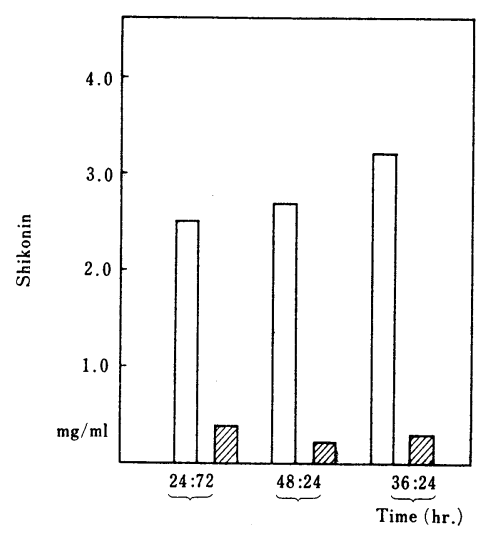

Fig-6 The amount of shikonin in the first extractive and second one in the case of bi-maceration. (key band $519 \pm 2 \mathrm{~m} \mu$ ) $\square \cdots \cdot$...the first extractive MIV.....the second extractive

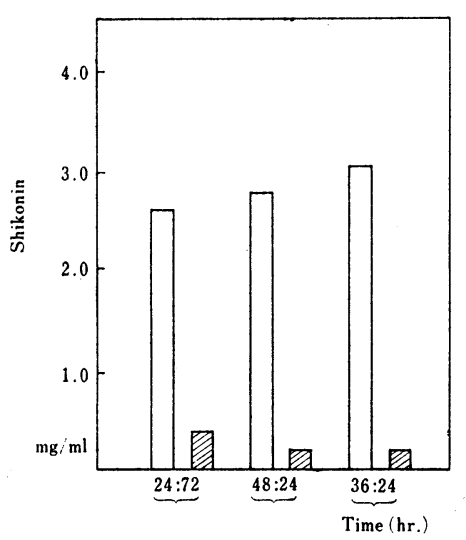

Fig-7 The amount of shikonin in the first extrative and second one in the case of bi-maceration. (key band $279 \pm 1 \mathrm{~m} \mu$ ) $\square$......the first extractive D......the second extractive
出時間をいろいろ変化させても, 第 2 回目の抽出液中よ りも第 1 回目の抽出液中において多いことが判る。

\section{3. 抽出液の臨床評価}

25名の被検者を用い，同愛記念病院にて臨床圾験を行 なった。抽出液を配合したクリームを用いて, 効果を評 価した。抽出液は Table-4 に示したようにクリーム中 に 5 \% 配合した。コントロールの場合, 抽出液をミリス チン酸イソプロピルに置きかえた。結果は Table-5 に 示す通りである。湿疹群では抽出液は慢性湿疹よりも急 性湿疹に対してより有効であるように思はれる。尋常性 痤瘡は対しても有効であるように思われる。尚副作用は 生じなかった。

Table-4 Formula of the cream containing the extractive and the control

\begin{tabular}{lcc}
\hline & $\begin{array}{l}\text { Cream containing } \\
\text { the extractive }\end{array}$ & Control \\
\hline White petrolatum & 5.0 & 5.0 \\
Stearyl alcohol & 25.0 & 25.0 \\
Extractive (IPM) & 5.0 & - \\
Isopropyl myristate & - & 5.0 \\
Propylene glycol & 12.0 & 12.0 \\
Sodium lauryl sulfate & 1.0 & 1.0 \\
Ethyl P-hydroxybenzoate & 0.025 & 0.025 \\
Propyl P-hydroxybenzoate & 0.015 & 0.015 \\
Water & to $100.0 \%$ & to $100.0 \%$ \\
\hline & &
\end{tabular}

Table-5 Clinical results of the extractive

\begin{tabular}{|c|c|c|c|c|}
\hline Symptom & $\begin{array}{l}\text { remark- } \\
\text { able }\end{array}$ & effective & $\begin{array}{l}\text { slightly } \\
\text { effective }\end{array}$ & $\begin{array}{l}\text { no- } \\
\text { change }\end{array}$ \\
\hline Acute eczema & & 4 & 1 & 2 \\
\hline Chronic eczema & & & 4 & 1 \\
\hline Acne vulgaris & 1 & 2 & 6 & 4 \\
\hline
\end{tabular}

\section{4. 考 察}

$4 \cdot 1$ 実験 $2 \cdot 3,2 \cdot 4$, から抽出の方法としては得られ た抽出中のシコニンの濃度, 安定性, 応用性から, 冷浸 法が紫雲高を調製する伝統的方法に比し考慮する価值が あると思われる。本研究にて, 試験された試料の中では シリスチン酸イソプロピルが最良の抽出剤と思われた。 ミリスチン酸イソプロピルと生薬の間の抽出メカニズム 等については更に検討したいと考えている。

$4 \cdot 2$ 実験 $2 \cdot 5,2 \cdot 6,2 \cdot 7$, 上りミリスチン酸イソプロ ピルを用いた抽出方法に関しては, 回分浸漬, 再冷浸の 場合共, 第 1 回目の抽出液中にほとんどのシコニンが抽 出される。回分浸漬, 再冷浸共, 唯 1 回の抽出に比し, 
大きい効果があると思えない。また抽出液調製のために は，冷浸時間として 72 時間を取るのが望ましい。

$4 \cdot 3$ 抽出液の臨床評価から充分なる臨床例が少なく, 断言することは困難であるが，抽出液は軽度の尋常性痤 瘡や急性湿疹に対して有効であると思われる。これは, シコニンはジハイドロキシナフトキノン型化合物で酸化 還元の両作用をもち, 皮膚機能の異状を調整するという 考2えの一端をになっているとも考えられる。

\section{5. 総 括}

化粧品原料を使用し，紫根の有効成分の抽出に関して 実験を行なった。抽出の方法に関しては, 冷浸法が伝統 的方法に比して考慮する価值があると思われた。また試 験された抽出剤ではミリスチン酸イソプロピルが最良の 抽出剤であった。臨床結果から抽出液は軽度の尋常性痤 瘡や急性湿疹に対し有効であると思われた。
本文の主旨については昭和 45 年 9 月バルセロナにお ける第 6 回 IFSCC 大会で講演した。

(昭和 46 年 4 月 4 日受理)

参 考 文 献

1）沢田玄弘，東北医，29，903，(1903）

2) 稲垣 勲外, 名古屋市立大学薬学部年報, No. 15 , 27, (1967)

3）猿橋 泰, 信州医誌, 9, No. 1, 230 (1961)

4) 渡辺 武外, 日本東洋医学会会誌, 5, No. 4, 19 (1955)

5) Yoshimasa. Hirata. etc, Tetrahedron Letters., No. 52, 4737 (1965)

6) Yoshimasa. Hirata. etc, Tetrahedron Letters. No. 31, 3677 (1966)

7) 黒田チカ, 日本化学雑誌, 39, 1051, (1918)

8) Brockmann. H., Annalen., 521, 1 (1936) 